\title{
The Development of Moral Imagination
}

\author{
Darcia Narvaez, University of Notre Dame
}

Kellen Mrkva, University of Colorado-Boulder

Narvaez, D. \& Mrkva, K. (2014). Creative moral imagination. In S. Moran, D. H. Cropley \& J. C. Kaufman (Eds.), The Ethics of Creativity (pp. 25-45). New York, NY: Palgrave MacMillan. 
A man, to be greatly good, must imagine intensely and comprehensively; he must put himself in the place of many others...the great instrument of moral good is the imagination" (Byron Percy Shelley, 1821, p. 13).

The everyday world is populated with opportunities to consciously steer through the shoals of social relationships and decide what sort of agent to be. In fact, research into mental preoccupations indicates that individuals ponder moral and relational issues much of the time (Klinger, 1978). Thus, on a daily basis people employ one of humanity's greatest gifts—moral imagination. But what fosters the development of moral imagination and determines to what extent it is used to benefit humanity? How does the morally imaginative individual utilize emotional and social experiences, reasoning, and selection to produce imaginative moral action? We address these questions.

The interest in psychological research on morality is growing rapidly (Haidt, 2007) and spreading to a large number of fields. Yet it is rare to encounter a moral psychology study which examines creativity or theorists who give much room for creativity in their accounts of moral functioning. Though there is at least some empirical research which will shed light on these topics, John Dewey's philosophical accounts may provide the greatest insights.

Dewey's conceptions of moral imagination perhaps best advanced understanding of the relationship between creativity and morality (Fesmire, 2003). He conceived imagination as a dramatic rehearsal in which people creatively explore and rehearse alternative courses of actions such that likely outcomes and impacts on others will guide moral decisions. This involves coauthoring the future with others through dialogue and feedback on imagined alternatives but also developing keen perception and flexible response to each situation. 
We will discuss moral imagination in similar terms to Dewey, but must first explain its relationship with creativity. Creativity has been defined as the ability to generate ideas which are original and unexpected, as well as useful or important (Sternberg, 1999) ${ }^{1}$. Moral imagination involves not only the ability to generate useful ideas, but also abilities to form ideas about what is good and right, and to put the best ideas into action for the service of others. The use of moral imagination involves exploring alternative actions and possibilities while being sensitive to the people, situation, and lifescapes at hand (Fesmire, 2003).

\section{Place of moral imagination:}

The prevailing view on the interaction between creativity, deliberation, and morality is captured by deontological philosophy. This perspective emphasizes moral deliberation as conscious reasoning, which is assumed to exist apart from emotion (Kant, 1949). Emotions are considered to be inconsistent, unreliable and irrational, and thus, to be avoided. A deontological approach has little room for moral imagination. In fact, imagination was considered to be in the realm of aesthetics, and outside of morality (Johnson, 1993). Indeed, situations typically discussed are those with clear rules. Kohlberg's measures pitted values against one another and scored responses within certain established boundaries. The role of creative and practical thinking and the influence of emotions and situational considerations were downplayed if not considered completely irrelevant to the goal of measuring moral reasoning capacities (Fesmire, 2003).

However, explicit reasoning is insufficient for the moral life. From a neurobiological perspective, the emphasis on conscious reasoning and a selection of principles is dominated by the intellect ('left-brain,' McGilchrist, 2009). The intellect typically comprises the conscious 
aspects of the mind which tend to minimize the vast tacit knowledge of and behavioral control by the rest of the brain. When a person relies on intellect alone, it signals that the intuitive mind and emotional intelligence are underutilized or underdeveloped (Narvaez, forthcoming).

In contrast to a heavy emphasis on application of reason to moral decisions and judgments, other philosophers emphasize emotion as the source of moral judgment. Moral judgments spring forth without effort or worry. Reason is used only to defend intuitive response (Haidt, 2001; Hume, 1739/1969). Building on Hume's view, Haidt (2001) proposed a social intuitionist theory that emphasizes instantaneous moral judgment (defined as evaluations of other people's actions and characters).As with deontological studies, the prototypical situations and methods deployed by Haidt and others do not enlist creativity. The unusual and emotionally strident situations create a quick positive or negative response which bias the conclusions made about reason, creativity, and morality (Monin, Pizarro, \& Beer, 2007). A third perspective directly addresses creativity in moral situations. Building on social intuitionism's view that reasoning is used for post-hoc rationalization, Ariely and colleagues conclude that creativity may actually increase unethical behavior (Gino \& Ariely, 2012). This is because creativity makes individuals better at inventing justifications for cheating and more skilled at defending personal moral goodness after moral violations. In one study, priming individuals with creative words led to more cheating, suggesting to the authors a causal link between creativity and cheating. Despite these concerns, we believe, like John Dewey, Mark Johnson and others, that moral imagination contributes positively to moral functioning in most circumstances. ${ }^{2}$ Moral imagination relies on different types of intelligence — cognitive, social, and emotional. The latter may be key for the others. 


\section{Emotion and Moral Development}

When emotion systems are misdeveloped, morality can go awry. Early life shapes the emotional and cognitive capabilities that underlie morality and imagination (Greenspan \& Shanker, 2004). Children are born with only one quarter of the brain developed, caregivers coconstruct $75 \%$ of the brain (for full-term infants) in the first years after birth (Trevathan, 2011). As a dynamic system, early life experience on multiple levels sets the stage for the rest of life. Caregivers shape the thresholds for numerous brain/body circuitries, and much of this entails neuroendocrine and emotion systems (Meaney, 2010; Schore, 2003a, 2003b). Too much stress at the wrong times in the first years of life can foster a stress-reactive brain, setting up a selfprotective personality (Narvaez, 2008, forthcoming). For example, when infants don't receive physical comforting in timely ways, the vagus nerve can be mistuned, leading to long term difficulties with social relations, as well as numerous health problems (Porges, 2011; Narvaez, in press). When an infant is distressed too much during gestation or postnatal life, the hypothalamic-pituitary-adrenal axis (HPA) can be tuned to being hyper (or hypo) active (Lupien et al, 2009). This affects imagination and creativity. Children who suffer from posttraumatic stress disorder have difficulty with daydreaming and symbolic play which consolidates meaning, affect and representation (Reid, 1999; Slade, 1994; 1987). Whenever the stress response is active it draws energy away from higher order thinking capacities, influencing how and how well a person imagines and relates to others (Sapolsky, 2004). But if stress and trauma occur early in life, systems never reach optimal trajectories (Shonkoff et al., 2012). Well-rehearsed stress states become traits. In this way neurobiological systems influence morality, setting up propensities to 
use different social and moral mindsets. What the brain's capacities look like has much to do with early life experience when brain system connections are being established.

Many philosophical traditions and psychological theories underestimated the role emotion plays in moral functioning, although there have been some exceptions (e.g. Hume). Even among those who emphasize emotion descriptively, emotion has been overwhelmingly viewed as disruptive normatively and as impairing moral judgment (Ben Ze'ev, 2000). Philosophers have viewed emotion as passive, undependable, and even primitive and bestial. In reality, individuals use their emotional experience to think in inclusive and integrative ways (Isen \& Daubman, 1984), build social relationships, and broaden creative possibilities (Fredrickson \& Branigan, 2005).

In recent decades, it has become clear that emotions serve as informatory guides to adaptive judgments and behavior (Panksepp, 1998; Slovic, Finucane, Peters, \& McGregor, 2002). They serve as cues to value, the relevance of stimuli, and whether our actions are successful (Panksepp, 1998). In the moral domain specifically, they reflect our goals and values and help us respond flexibly and adaptively (Pizarro, 2000). They can be used imaginatively in attending to the morally-relevant aspects of a situation, selecting moral goals, integrating values, and being sensitive to other individuals (see "everyday moral imagination" section). They form the substrate for moral motivation and action (Blasi, 1999). Multi-ethics theory takes this perspective.

\section{Extending Dewey's Moral Imagination}


Triune ethics theory (TET; Narvaez, 2008) asserts that humans rely on a variety of neurobiologically-derived moral mindsets derived from evolved global brainstates (MacLean, 1990). Individuals can habitually favor one mindset or fluctuate among several. Before delineating the theory in detail, we note the tremendous overlap and agreement between Dewey's and TET's conceptions of moral imagination and moral functioning.

Both theories emphasize that moral imagination requires being sensitive to the morallyrelevant aspects of a situation, envisioning different alternatives for action, and thinking about the ramifications of an action for people involved (Narvaez \& Vaydich, 2008; Somerville, 2006; Fesmire, 2003). These capacities rely on finely tuned perception, which is highly affected by where one habitually places attention (Murdoch, 1989). If one's attention is captivated by perceived threat cues, then moral perception will be narrowed to what is self-protective. Second, both Dewey and TET emphasize the social nature of moral imagination, and the need for flexible, open thinking. Studies examining TET have found strong correlations between moral imagination and both openness to experience and agreeableness. They also posit that flexible thinking and the ability to adapt in ongoing social relationships characterize imaginative behavior. Dewey asserts that individuals with flexibility and the ability to deal with ambiguity in imaginative ways are better able to perceive moral situations and act effectively. Dewey views moral behavior as co-authored with others and as occurring in uncertain or ambiguous situations. Third, both TET and Dewey emphasize that the moral imagination involves self-regulation or an ability to put beliefs and goals into action. Dewey idealizes the person who is able to regulate behavior based on the imagined effects and inspect beliefs for their value in action. Triune ethics goes so far as to posit neurobiological roots of the moral imagination in which individuals engage the prefrontal cortex to self-regulate, prevent harmful behaviors through "free won't", 
and engage in reflective abstraction. Fourth, both TET and Dewey emphasize the importance of harmony in dealing with multiple values such as autonomy and community. TET asserts the importance of coordinating emotion and reason, the conscious mind with the adaptive unconscious, and goals with mood and energy. Combining the insights of both Dewey's moral imagination and TET allows one to better understand the processes which moral exemplars engage in when facing a moral situation. Individuals can take advantage of the power and intelligence of the moral emotions while using regulation and metacognition to ensure they guide behavior towards fulfillment of moral goals and virtues.

\section{Multiple Ethics}

Triune Ethics Theory extends the keen insights of Dewey while delineating the developmental and neurobiological substrates of moral imagination. It develops a view of various moral mindsets that people rely on which are formed during reciprocal interactions with caregivers in early life and during other sensitive periods in life. The list of types is in Table 1.

There are certain emergent rules about getting along with others that develop in supportive environments and foster right-brain development (Schore, 1994; 2003a, 2003b). Optimal early life offers the experience of reciprocal interaction through intersubjectivity and mutual influence. Intersubjective responsivity — attending to and responding to social signaling in a collaborative manner-is a creative response. Babies are ready for playful, creative protonarrative co-construction with caregivers at birth (Trevarthen, 2005). Baby and caregiver create their own stories through reciprocal, sensitive communication. This type of "companionship care" fosters all three types of attachment (Narvaez, forthcoming). Protective attachment is like 
imprinting, a desire for physical proximity, and is evident even in abused children. Warmth attachment is emotional connection to the caregiver, which facilitates capacities for compassionate relationships. Companionship attachment offers an intellectual friendship, a cognitive sharing that fosters creative imagination.

Nurturing caregiving in early life fosters optimal right brain development, including the prefrontal cortex which is critical for moral imagination (Schore, 2003a, 2003b). Imaginative capacities in adults involve tacit knowledge, a trust in process, an indwelling in the other, whether object or person. Living through the mind of the Other involves an extended self (Polanyi, 1958). Moral imagination capacities emerge from social creativity, based on these intensive social experiences in early life (although there are other sensitive periods in life when the brain can be reshaped to some degree). Those who have responsive caregivers, whose needs are met without distress, are more likely to develop secure attachment and the neurobiological underpinnings of a socially adaptive personality and moral intelligence (Eisenberg, 2000; Narvaez \& Gleason, 2013). This is represented by capacities for an engagement ethic, relational attunement with compassionate capabilities (Narvaez, 2008, 2012, in preparation). When deliberative capacities are added to this base of relational attunement capacities, communal imagination can flourish. Communal imagination uses capacities for abstraction from the present moment, addressing moral concerns beyond the immediate but grounded in a relational web, based in well-honed social skills. This kind of broad sense of community was displayed by our hunter-gatherer cousins who were concerned with the welfare of all life forms, even into future generations (see Narvaez, 2013).

**PLACE TABLE 1 ABOUT HERE** 
One of the defining characteristics of the moral imagination in triune ethics theory is its ability to abstract and move beyond the present situation. This allows one to act on behalf of those not present, or on behalf of abstract ideas like justice (Narvaez, 2010). The capacity to act on behalf of these abstract ideas requires a coordination of reasoning with motivational and emotional processes. For communal imagination, empathy is a powerful source of moral behavior. When empathy-arousing stimuli are not present, the powers of imagination can still maintain engagement in moral behavior. It is believed that individuals who demonstrate longterm commitments to humanitarian or prosocial causes rely on an ethic of imagination by making moral concerns central to their identity, and selecting or seeking out situations which arouse their motivation and empathy to take action (Heath \& Heath, 2010; Pizarro, 2000). Failure to help others commonly occurs because empathy is not engaged (Trout, 2009). For individuals who do not imaginatively regulate and heighten their emotional responses adaptively, "sympathy is easily aroused but quickly forgotten" (Wilson, 1993).

In contrast, those with poor early care are likely to develop stress-reactive brains, making social interaction and an engagement ethic difficult. Stress-reactivity leads to a habitual safety ethic - shifting between different inegalitarian social orientations: an aggressive stance (bunker morality) or a withdrawing stance (wallflower morality). In those with sufficient physiological but less-than-optimal social experience in early life, the right brain is often underdeveloped, leading to a dominance of left-brain use (Schore, 1994, 2003a, 2003b; Siegel, 1999). In this case imagination can be divorced from compassion, resulting in the calculation of utility in detached imagination (emotional disengagement) or adoption of a non-imaginative ideology reflected in vicious imagination (inegalitarian relations). See Figure 1. 
Moral imagination can be handicapped by childrearing practices due to the misdevelopment of brain/body functions that occur when infants' basic need are not met (Narvaez, forthcoming). Evolved caregiving practices have been culturally discouraged, perhaps due to ignorance about their deep influence on development and lifelong capacities. The developmental niche that evolved for humans in early life includes: frequent on-demand breastfeeding for 2-5 years; nearly constant touch in the first years of life; responsiveness to the needs of the child so that the child does not become distressed; free self-directed play; multiple adult caregivers; positive expectation and support; and natural childbirth (Narvaez, Panksepp, Schore \& Gleason, 2012). 'Undercare' (when these components are missing) undermines not only cognitive and emotional intelligence but also moral creativity, for it is often the socialemotional systems that are underdeveloped with modern caregiving practices (Schore 1994, 2003a, 2003b; Trevarthen, 2005). Caregiving practices that violate evolved, expected care harm capacities for moral engagement and communal imagination and encourage the use of detached and vicious imagination, self-focused uses of imagination (Narvaez, 2012; 2013; forthcoming). Poor early care interferes with all capacities, from social, emotional to reasoning skills, encouraging both detached and vicious imagination.

Moral reasoning can be misused in two ways. First, when moral reasoning is calculative and divorced from relational empathy, imagination is limited as reasoning seeks to apply a rule to a situation (detached imagination). Calculative moral reasoning is harmful to moral imagination and action because it detaches from lived emotional experience and disengages social emotions. Actions originally viewed as immoral or even unthinkable can be justified among individuals who are detached from their prosocial emotions or are not experiencing 
empathy (Bandura, 1999). The road to habitual detached imagination may be lubricated with poor social intuition or emotional intelligence.

A second form of reasoning misuse occurs when individuals or groups take on a vicious imagination. Vicious imagination seeks dominance and control of others, overtly or covertly, demonstrating the superiority of the individual or group (e.g., in terms of lifestyle, ideas, values, efficiency). It too is detached from empathy but can be fueled also by anger. In this case moral reasons are used to justify actions or to confirm bias and strengthen preformed conclusions about inegalitarian relations. In extreme cases, individuals view human lives as secondary to their ends, and take evil action in a misguided effort to do good (Bandura, 1999). As examples of pathological altruism, Baumeister \& Vohs (2004) cite the Stalinist purges in Russia and the cultural revolution in China. In these and similar cases the desire to 'do good' was responsible for more deaths than actions considered "necessary evils" or based on revenge.

\section{Everyday Moral Imagination}

Early experiences, and reciprocal interactions with caregivers in particular, have tremendous influence on the moral orientations individuals develop. These moral orientations, in turn, influence everyday moral functioning. Multiple capacities are needed to respond to everyday moral situations with flexibility and imagination. The following section will address how individuals (1) select goals and actions, (2) develop habits, (3) integrate numerous values into a single decision, and (4) make sense of their actions and their identity in retrospect.

Moral focus. Imagination guides us in the selection of goals and action. Mark Johnson describes deep moral imagination: 
"We need to imagine how various actions open to us might alter our self-identity, modify our commitments, change our relationships, and affect the lives of others. We need to explore imaginatively what it might mean, in terms of possibilities for enhanced meaning and relationships, for us to perform this or that action. We need the ability to imagine and to enact transformations in our moral understanding, our character, and our behavior. In short, we need an imaginative rationality that is at once insightful, critical exploratory, and transformative." (p. 187).

Imagining how an action might turn out facilitates choices and the eventual taking of action. Gollwitzer and others have found that goals such as sending letters, dieting, exercising, and even performance on a helping behavior increase among those who imagine the actions they must take to achieve their desired outcome (Gollwitzer \& Sheeran, 2006).

Emotional experiences, imaginative or real, can alter judgments. Many of the abstract moral principles we come to endorse were formed as a result of an emotional experience that alters judgment. In some situations, we feel empathy for individuals who we judge negatively and come to change our higher-order principles as a result of our emotions in what Pizarro (2000) calls bottom-up correction. For example, Batson et al (1997) found that individuals had negative attitudes towards stigmatized groups such as the homeless but revised these attitudes after feeling empathy for the group. Learning about a homeless man's experiences which led to his present condition leads to greater sympathy the next time he is seen on the street (see Betancourt, Hardin, \& Manzi, 1992). Imagining and understanding another's reality can change how one thinks and may even instigate investigation into understanding the cause more deeply. An imagining individual uses abstraction capabilities with emotions engaged, becoming open to changing thinking as a result of the dramatic mental experience. The many pitfalls of making 
judgment can be minimized with an integration of emotion and reasoned judgment, resulting in helpful assistance directed to those who will be benefited most (Loewenstein \& Small, 2007). This occurs among those with greater moral expertise (Narvaez, 2006, 2010; Narvaez \& Lapsley, 2005).

Thinking in only abstract, philosophical terms leads to inferior moral decisions. Just as a person wanting to learn to drive a stick shift would not learn anything by pondering the matter outside of the car, we cannot learn much about moral action through detached or dispassionate thought. We must practice manipulating the stick shift and clutch within the process of driving. Similarly, moral imagination and action takes place in the stream of life. As we cooperate with others, we learn how to perform positive moral action. In Dewey's view (1908/2009), it is vital to think interactively and examine moral behavior in light of its effects on relationships.

Habits. Habits are formed from immersion in environments that provide feedback on what works to get aims or needs met (Hogarth, 1999). Immersion trains up implicit knowledge and automatic responses. So it is best to choose environments that shape intuitions and habits one wishes to have (Narvaez, 2006). During moral action and reflection afterwards, people gain a wealth of experiential or implicit knowledge to use in similar moral situations in the future (Narvaez and Lapsley, 2005).

Creative integration. Creative individuals draw on the experiences and successes of others. Exceptionally moral individuals are able to see the "bright spots" of what is currently helping individuals, and make connections to how they can use this knowledge to help people in new and larger ways (Heath \& Heath, 2010). For example, members of a non-governmental organization (NGO) with a very small budget found that families in one community had the same amount of money as other communities but unlike the others did not suffer from stunted 
growth or malnutrition because they took advantage of a few key foods and cooking techniques. The NGO noticed this "bright spot," imagined its application elsewhere and worked to educate other communities about the same techniques. Drawing on prior successes in cooperating with people with different and conflicting values, imaginative individuals are capable of using a number of values as they reason about issues (Tetlock, 2005), reconciling multiple considerations (Wallace, 1988), and taking into account their responsibilities (Frankfurt, 1993). Both triune ethics theory and Dewey's theory of moral imagination address the importance of community and individual autonomy and of finding harmony between competing values (Fesmire, 2003; Narvaez, 2008). During the highest forms of moral imagination there is a double aim of valuing community-wide interests and maintaining respect for individual autonomy (rather than pitting one against the other; Rest et al, 1999). Frimer, Walker, Dunlop, Lee, and Riches (2011) found that moral exemplars who were especially altruistic and influential were able to act in accordance with values of agency and communion in the same actions, rather than favoring one or the other. Individuals who develop moral complexity and imagination are able to see a greater number of values as relevant to a situation rather than letting one override the others (see Baron \& Spranca, 1997). They reason with complexity and see opportunities to fulfill multiple values at once - perceiving ways that values can be harmonious rather than in conflict (Narvaez, 2010; Narvaez \& Mrkva, forthcoming).

Reflection. Reflection abilities develop from guided practice within particular domains. Taking time to consider routine behavior or analyze chosen actions facilitates further understanding. Through continued reflection the growth process continues well after an action is completed. As implicit knowledge develops, action can become more automatic. People make attributions of responsibility and blame, evaluate the quality of decisions (Blum, 1994), and 
make sense of self-identity in light of behavior (Wainryb \& Pasupathi, 2010), altering

perspectives for the next time a similar situation occurs. Throughout the reflection process, imagination allows individuals to see opportunities to shape self-identity through action, to act in accordance with deeply held values, and establish a more developed self as a result. MET posits the ability to frame behavior and establish a life narrative based on one's goals and behavior as an aspect of the moral imagination (Narvaez, 2010).

\section{Creativity, intelligence, and moral imagination}

Individual goal preferences are influenced by early experience-how open to others, how self-protective, how capable of thinking and reflecting, and so on. Even beyond childhood, individuals are influenced by their culture and social context, and many seek out and reflect on the aspects of culture and the environments that influence them (Pizarro, Detweiler-Bedell, \& Bloom, 2006). However, other individuals do not reflect a great deal but stay with learned habits and traditions within a small sphere, relying instead on others to tell them how to think or behave. In a morally-pluralistic society, some individuals select moral goals, principles, and virtues that they wish to enact from a large variety of possibilities. Individuals modify their views through interactions with others, whether parents or acquaintances, and whether the idea is mainstream or radical. Pizarro (Pizarro et al, 2006) has described how individuals often do not passively accept the moral views of culture or parents, and how even a book or an interaction with a stranger can lead to a dramatic change in moral beliefs, especially among children who are reflective or imaginative.

The opportunity to step outside of the usual boxes of habit or intellectual detachment can engage the imagination, opening up attention so that one can look at the world with fresh eyes, as 
if for the first time (Hadot, 2011). For communal imagination, it means adopting a 'heart' view, engaging a sense of emotional connection to others (right-brain dominant view), rather than using the filter of 'utility' to narrow it (left-brain dominance). Reliance on rigid formulas, inflexible rules, or impersonal reasoning is, in Dewey's view (1908/2009) and ours, "the death of all high moral responsibility" (page 60). Instead, moral imagination requires an avoidance of simplistic thinking and a degree of ideological complexity rather than rigidity. In both research on creativity and political ideologies, thinking that includes a strong need for closure, ambiguity intolerance, and dogmatism leads to less adequate decision making. For example, need for closure has been linked with both lower creativity and more conformist, authoritarian moral ideologies; ambiguity tolerance is consistently correlated with creativity and is also important in generating a morality that is not overly simplistic, reductive, and idealistic in viewing values as never conflicting (Tegano, 1990; Yurtsever, 2000).

In several studies, the present authors have examined explicit adoption of characteristics representing safety, engagement or communal imagination ethics. Unlike the few (to this point) findings linking creativity and moral behavior, communal imagination ethical orientation positively relates to a variety of moral characteristics and behaviors. These include honesty and integrity, empathy, perspective-taking, prosocial moral identity, action for the less fortunate, humanism, openness to experience and growth mindset (Narvaez, Brooks, \& Mattan, 2011; Narvaez, Brooks, \& Hardy, 2013). It should be emphasized that the first pair of these relationships (between communal imagination and both honesty and integrity) reveal a different picture than that portrayed by Ariely (2012; Gino \& Ariely, 2012). Even if some measures of creativity are linked to cheating and poor integrity, communal imagination orientation is clearly not. It is also notable that communal imagination is linked not only to judgment and personality 
measures (e.g. integrity) but also behavior ones (e.g. action for the less fortunate), and not only thinking measures (humanism) but also emotional ones (e.g. empathy). Further investigations are needed to determine whether these relationships are causal.

\section{Creative Moral Exemplars}

It is clear that moral creativity does not matter much unless an individual is able to choose one of the most useful ideas from those generated and act on it. Capacities for moral sensitivity, moral motivation, and follow through must also be cultivated (cite Rest, 1983, 1986; Narvaez \& Rest, 1995). James Rest $(1983,1986)$ perhaps best captured the complete picture of moral functioning in his four-component model. He argued that moral sensitivity, moral judgment, moral motivation, and moral action each play important roles in moral decisions. Moral reasoning alone does not capture the whole picture. Moral sensitivity entails moral perception and interpretation - the ability to notice and identify the important ethical aspects of a situation, Moral judgment entails involves choosing the morally ideal course through reasoning. Moral motivation comprises prioritizing the moral action over other options. Moral action involves having the ability and character to act, through will and knowledge, on one's moral goals and judgments.

The creative moral exemplar possesses a vast variety of skills that function as a toolkit. The skills mentioned throughout this paper each fit into one or more of Rest's components. Among those already discussed, some fit best into the category of moral sensitivity. These include using emotion to feel with others and perceive their needs. Abilities to select goals and values to endorse, integrate numerous values into a single decision, and generate several ideas 
about how to act seem to fit best into the moral judgment category. Skills involving the use of emotion and regulation techniques to maintain motivation and focus on a problem and perhaps forming one's identity in light of actions are skills of moral motivation. Finally, skills of moral action include cultivating good habits and selecting among the opportunities for moral action or among the values one can apply.

Individuals high in moral imagination are more likely to extend regard to individuals in their environments who are members of outgroups or strangers (Mrkva \& Narvaez, in press). They are less likely to stigmatize the homeless based on information suggesting responsibility for their condition, more likely to favor policies which promote greater respect for each life (e.g. whether in the US or abroad) and less likely to blame victims or ignore individuals in need because of their status as strangers or an "other".

Many of these components are included in the right-brain capacity for mindfulness, a flexible engagement in the present, and ability to see connections, be sensitive to context, and notice new elements of a situation. Mindfulness requires creativity but does not stop there-it also requires that one be engaged in the present moment, sensitive to others in their immediate environment, and willing to interact with and help others if the feelings and actions of others suggest that they are in need or could be assisted in some way. Mindfulness entails the ability to empathize with others and experience their emotions, but imaginative moral functioning must also use this experience to guide changes in thought. In this way, mindfulness can influence moral reasoning, judgment, and action as much as sensitivity, in a type of bottom-up correction (Pizarro, 2000). We can see this in a recent trend identified by Ray and Anderson (2000). They describe the emergence of "cultural creatives." These individuals appear to blend morality and 
creative imagination, as is visible from the set of characteristics listed in Table 2 (ten or more of these are indicative of being a cultural creative).

**Place Table 1 about here**

\section{Conclusion}

Imagination (as a mental faculty), emotion (as a psycho-bio-social faculty), and morality (as an internalized mental frame) interact developmentally in different ways based on the experiences of a person. These differential interactions can result in different dispositions and types of imagination: Detached (little emotional engagement with the world), Vicious (aggressive emotional interaction), Engaged (present-focused positive interaction), and Communal (extended collaborative positive interaction). There are different amounts and quality of creativity demonstrated in each of these types of moral imagination. Although high levels of both intelligence and creativity may be demonstrated in Detached and Vicious imagination, these forms are more self-focused forms, limited in their scope of care and consequences for others, and lead to intentional or unintentional harmful outcomes. Communal imagination, in contrast, maintains an all-inclusive sense of caring relation in pondering and taking action as a creative collaboration (John-Steiner, 2000), demonstrating the highest form of ethical sensitivity.

Morality is "the ongoing imaginative exploration of possibilities for dealing with our problems enhancing the quality of our communal relations, and forming significant personal attachments that grow" (Johnson, 1993, p. 209). Current cultural practices do not well serve the development of the more positive forms of moral imagination. There are more supports for Detached and Vicious imagination than for Engaged and Communal imaginations, including societal (e.g., undercare, priority of monetary success) and educational (schooling that sets aside emotional and social aspects of life) forms. Engaged and Communal moral imaginations require 
good beginnings, with nurturing caregiving and empathic relationships during sensitive periods. These experiences foster right-brain, present-oriented capacities (including self-regulation, behavior inhibition, empathy (Narvaez, Wang et al., 2013). Engaged and Communal imaginations may also require ongoing safe and supportive environments. Creative moral imagination allows individuals and communities to grow in their virtue, deepening and extending moral regard and sensitivity to a greater circle of life. 


\section{Footnotes}

2 Creativity has been defined as the ability to generate ideas which are original and unexpected, but are considered useful or important (Sternberg, 1999). Moral imagination involves not only the ability to generate useful ideas, but also abilities to form ideas about what is good and right, and to put the best ideas into action for the service of others. This involves sensitivity to the people and lifescapes at hand.

3 However, we must not overplay our cards and descriptively assert that imagination is used in all moral decisions. There are many occasions when we make moral judgments based on habit or expediency; failing to consider the uniqueness of the situation. If we are correct about the significant role creativity plays in our moral lives, imagination and especially social imagination deserve more attention from psychological researchers and ethical theorists. 


\section{References}

Ariely, D. (2012). The (honest) truth about dishonesty: How we lie to everyone-especially ourselves. New York, NY: HarperCollins Publishers.

Bandura, A. (1999). Moral disengagement in the perpetration of inhumanities. Personality and Social Psychology Review, 3, 193-209.

Baron J, \& Spranca, M. (1997). Protected values. Organizational Behavior and Human Decision Processes, 70, 1-16.

Batson, C.D., Polycarpou, M.P., Harmon-Jones, E., Imhoff, H., Mitchener, E.C., Bednar, L.L., Klein, T.R., \& Highberger, L. (1997). Empathy and attitudes: Can feeling for a member of a stigmatized group improve feelings toward the group? Journal of Personality and Social Psychology, 72, 105-118.

Baumeister, R. F., \& Vohs, K.D. (2004). Four roots of evil. In A. G. Millerm (Ed.)., The social psychology of good and evil (pp.85-101). New York: Guilford.

Ben-Ze'ev, A. (2000). The subtlety of emotions. Boston: MIT Press.

Betancourt, H., Hardin, C., \& Manzi I. J. (1992). Beliefs, value orientation, and culture in attribution processes and helping behavior. Journal of Cross Cultural Psychology, 23, $179-195$.

Blasi, A. (1999). Emotions and moral motivation. Journal for the Theory of Social Behavior, 29, 1-19.

Blum, L. (1994). Moral perception and particularity. New York: Cambridge University Press.

Dewey, J. (1908/2009). Ethics. Ithaca, NY: Cornell University Library.

Eisenberg, N. (2000). Emotion, regulation, and moral development. Annual Review of Psychology, 51, 665-697. 
Fesmire, S. (2003). John Dewey and the moral imagination: Pragmatism in ethics. Bloomington: Indiana University Press.

Frankfurt, H. (1993). What we are morally responsible for. In J.M. Fischer \& M. Ravizza (Eds.), Perspectives on moral responsibility (pp. 286-294). Ithaca, NY: Cornell University Press.

Fredrickson, B. L., \& Branigan, C. (2005). Positive emotions broaden the scope of attention and thought-action repertoires. Cognition \& Emotion, 19(3), 313-332.

Frimer, J. A., Walker, L. J., Dunlop, W. L., Lee, B. H., \& Riches, A. (2011). The integration of agency and communion in moral personality: Evidence of enlightened self-interest. Journal of Personality and Social Psychology, 101, 149-163.

Gibbs, J. C. (2003). Moral development and reality: Beyond the theories of Kohlberg and Hoffman. New York: Sage.

Gino, F., \& Ariely, D. (2012). The darks side of creativity: Original thinkers can be more dishonest, Journal of Personality and Social Psychology, 102, 445-459.

Greenspan, S.I., \& Shanker, S.I. (2004). The First idea. Cambridge, MA: Da Capo Press.

Hadot, P. (2011). The present alone is our happiness (M. Djaballah \& M. Chase, transl.). Stanford: Stanford University Press.

Haidt, J. (2001). The Emotional Dog and Its Rational Tail: A Social Intuitionist Approach to Moral Judgment, Psychological Review, 108, 814-834.

Haidt, J. (2007). The new synthesis in moral psychology. Science, 316, 998-1002.

Heath, C., \& Heath, D. (2010). Switch: How to change things when change is hard. New York, NY: Broadway Books.

Hogarth, R. M. (2001). Educating Intuition. Chicago: University of Chicago Press. 
Hume, D. (1969). A treatise of human nature. London: Penguin. (Original work published 1739 $\& 1740)$

Isen, A. M., \& Daubman, K. A. (1984). The influence of affect on categorization. Journal of Personality and Social Psychology; Journal of Personality and Social Psychology, 47(6), 1206.

Johnson, M. (1993). Moral imagination. Chicago: University of Chicago Press.

Kant, I. (1949). Fundamental principles of the metaphysics of morals. New York: Liberal Arts Press.

Klinger, E. (1978). Modes of normal conscious flow. In K.S. Pope \& J.L. Singer (Eds.), The stream of consciousness: Scientific investigations into the flow of human experience (pp. 225-258). New York: Plenum.

Loewenstein, G. \& Small, D. (2007). The scarecrow and the tin man: The vicissitudes of human sympathy and caring. Review of General Psychology, 11, 112-126.

Lupien, S. J., McEwen, B. S., Gunnar, M. R., \& Heim, C. (2009). Effects of stress throughout the lifespan on the brain, behaviour and cognition. Nature Reviews Neurosciences, 10, 434445.

McGilchrist, I. (2009). The master and his emissary: The divided brain and the making of the western world. New Haven, CT: Yale University Press.

Meaney, M. (2010). Epigenetics and the biological definition of gene $\mathrm{x}$ environment interactions. Child Development, 81(1), 41-79.

Monin, B., Pizarro, D., \& Beer, J. (2007). Emotion and reason in moral judgment: Different prototypes lead to different theories. In K. D. Vohs, R. F. Baumeister, \& G. Loewenstein 
(Eds.), Do emotions help or hurt decision making? New York: Russell Sage Foundation Press.

Mrkva, K., \& Narvaez, D. (in press). Moral psychology and the "cultural other": Cultivating an openness to experience and the new. In B. Zizek \& A. Escher (Eds.), Ways of approaching the strange. Steiner Verlag.

Mrkva, K., \& Narvaez, D. (2012). Reflection, creativity, and moral identity. Unpublished raw data.

Murdoch, I. (1989). The sovereignty of good. London: Routledge. (first published in 1970)

Narvaez, D. (2006). Integrative Ethical Education. In M. Killen \& J. Smetana (Eds.), Handbook of Moral Development (pp. 703-733). Mahwah, NJ: Erlbaum.

Narvaez, D. (2008). Triune ethics: The neurobiological roots of our multiple moralities. New Ideas in Psychology, 26, 95-119.

Narvaez, D. (2010). Moral complexity: The fatal attraction of truthiness and the importance of mature moral functioning. Perspectives on Psychological Science, 5, 163-181.

Narvaez, D. (2012). Moral neuroeducation from early life through the lifespan. Neuroethics, 5(2), 145-157. doi:10.1007/s12152-011-9117-5

Narvaez, D. (2013). Development and socialization within an evolutionary context: Growing up to become “A good and useful human being." In D. Fry (Ed.), War, Peace and Human Nature: The convergence of Evolutionary and Cultural Views (pp. 643-672). New York: Oxford University Press.

Narvaez, D. (in press). Neurobiology and moral mindsets. In K. Heinrichs \& F. Oser (Eds.), Moral and Immoral Behavior: Theoretical and Empirical Perspectives on Moral Motivation (pp. 289-307). Rotterdam: Sense Publishers. 
Narvaez, D. (forthcoming). The neurobiology and development of human morality. New York: W.W. Norton.

Narvaez, D., Brooks, J., \& Hardy, S. (2013). A multidimensional approach to moral identity: early life experience, prosocial personality, and moral outcomes. Manuscript submitted for publication.

Narvaez, D., Brooks, J.A., Gleason, T., Wang, L., Cheng, A., Lefever, J., \& Centers for the Prevention of Child Neglect (2011). Child outcome effects of the environment of evolutionary adaptedness: Breastfeeding experience and touch at 30 and 36 months. Society for Research in Child Development, Montreal.

Narvaez, D., Brooks, J., \& Mattan, B. (2011). Triune ethics moral identities are shaped by attachment, personality factors and influence moral behavior. Annual meeting of the Society for Personality and Social Psychology, San Antonio.

Narvaez, D., \& Gleason, T. (2013). Developmental optimization. In D. Narvaez, J., Panksepp, A. Schore, \& T. Gleason (Eds.), Evolution, Early Experience and Human Development: From Research to Practice and Policy (pp. 307-325). New York: Oxford University Press.

Narvaez, D., Gleason, T., Brooks, J. Wang, L., Lefever, J., Cheng, A., \& Centers for the Prevention of Child Neglect (2012). Longitudinal effects of ancestral parenting practices on early childhood outcomes. Manuscript submitted for publication.

Narvaez, D., Gleason, T., Cheng, A., Wang, L., \& Brooks, J., (2012). Nurturing Parenting Attitudes Influence Moral Development in Three-Year-Olds. Manuscript submitted for publication. 
Narvaez, D. \& Lapsley, D. K. (2005) The psychological foundations of everyday morality and moral expertise, in: D. Lapsley \& C. Power (Eds.), Character psychology and character education (Notre Dame, IN, University of Notre Dame Press), pp. 140-165

Narvaez, D., Panksepp, J., Schore, A., \& Gleason, T. (Eds.) (2013). Evolution, Early Experience and Human Development: From Research to Practice and Policy. New York: Oxford University Press.

Narvaez, D., \& Rest, J. (1995). The four components of acting morally. In W. Kurtines \& J. Gewirtz (Eds.), Moral behavior and moral development: An introduction (pp. 385-400). New York: McGraw-Hill.

Narvaez, D., \& Vaydich, J. (2008). Moral development and behavior under the spotlight of the neurobiological sciences. Journal of Moral Education, 37, 289-313.

Narvaez, D., Wang, L., Gleason, T., Cheng, A., Lefever, J., \& Deng, L. (in press). The Evolved Developmental Niche and sociomoral outcomes in Chinese three-year-olds. European Journal of Developmental Psychology.

Panksepp, J. (1998). Affective neuroscience. New York: Oxford University Press.

Pizarro, D. (2000). Nothing more than feelings? The role of emotions in moral judgment. Journal for the Theory of Social Behaviour, 30, 355-455.

Pizarro, D., Detweiler-Bedell, B., \& Bloom, P. (2006). The creativity of everyday reasoning: Empathy, disgust and moral persuasion. In J. Kaufman, J. Baer (Eds.), Creativity and reason in cognitive development, Cambridge University Press, Cambridge, UK (2006), pp. 81-98.

Polanyi, M. (1958). Personal knowledge: Towards a post-critical philosophy. Chicago: University of Chicago Press. 
Porges, S. W. (2011). The polyvagal theory: Neurophsiologial foundations of emotions, attachment, communication, self-regulation. New York: W.W. Norton.

Ray, Paul H.; Sherry Ruth Anderson (2000). The Cultural Creatives: How 50 Million People Are Changing the World (illustrated ed.). New York: Harmony Books.

Reid, S. (1999). Autism and trauma. Autistic post-traumatic developmental disorder. In A.

Alvarez \& S. Reid (Eds.), Autism and personality. Findings from the Tavistock Autism Workshop, (pp. 93-109). London: Routledge.

Rest, J. (1983). Morality. In P. H. Mussen (Series Ed.) \& J. Flavell \& E. Markman (Vol. Eds.), Handbook of child psychology: Vol. 3, Cognitive Development (4th ed., pp. 556-629). New York: Wiley.

Rest, J.R. (1986). Moral Development: Advances in research and theory. New York: Praeger Press.

Rest, J., Narvaez, D., Bebeau, M.J., \& Thoma, S.J. (1999). Postconventional moral thinking: A neo-Kohlbergian approach. Mahwah, NJ: Lawrence Erlbaum Associates.

Sapolsky, R. (2004). Why zebras don't get ulcers, 3rd ed. New York, NY: Holt.

Schore, A.N. (1994). Affect regulation and the origin of the self. Hillsdale, NJ: Erlbaum.

Schore, A. (2003a). Affect regulation and the repair of the self. New York: Norton.

Schore, A. (2003b). Affect dysregulation and disorders of the self. New York: Norton.

Shelley, P.B. (1821). A defence of poetry. Downloaded on September 162012 from http://www.bartleby.com/27/23.html

Shonkoff, J.P., Garner, A.S. The Committee on Psychosocial Childhood, Adoption, and Dependent Care, and Section on Developmental and Behavioral Pediatrics, Dobbins, M.I.,. Earls, M.F., McGuinn, L., ... \& Wood, D.L. (2012). The lifelong effects of early 
childhood adversity and toxic stress. Pediatrics, 129, e232. DOI: 10.1542/peds.20112663

Slade, A. (1987). The quality of attachment and symbolic play. Developmental Psychology, 23, 78-85.

Slade, A. (1994). Making meaning and making believe: Their role in the clinical processs. In A. Slade \& D. Wolf (Eds.), Children at play: clinical and developmental approaches to meaning and representaion, (pp. 81-110). New York: Oxford University Press.

Slovic, P., Finucane, M., Peters, E., \& MacGregor, D. G. (2002). Rational actors or rational fools: Implications of the affect heuristic for behavioral economics. Journal of Socioeconomics, 31(4), 329-342.

Somerville, M. (2006). The ethical imagination: Journeys of the human spirit. Toronto: House of Anansi Press.

Sternberg, R. J. (Ed.). (1999). Handbook of creativity. New York: Cambridge University Press.

Tetlock P. E. (2005). Expert political judgment: How good is it? How can we know? Princeton, NJ: Princeton Univ. Press.

Trevarthen, C. (2005). Action and emotion in development of the human self, its sociability and cultural intelligence: Why infants have feelings like ours. In J. Nadel and D. Muir (Eds.) Emotional Development (pp. 61-91). Oxford: Oxford University Press.

Trevathan, W.R. (2011). Human birth: An evolutionary perspective, $2^{\text {nd }}$ ed.. New York: Aldine de Gruyter.

Wainryb, C., \& Pasupathi, M. (2010). Political violence and disruptions in the development of moral agency. Child Development Perspectives, 4, 48-54.

Wallace, J.D. (1988). Moral relevance and moral conflict. Ithaca, NY: Cornell University Press. 
Wilson, J.Q. (1993). The moral sense. New York: Free Press.

Yurtsever, G.(2000). Ethical beliefs and tolerance of ambiguity. Social Behavior and Personality: An International Journal, 28 (2), 141-148. 
Table 1. Basic Mindsets in Multi-Ethics Theory

\begin{tabular}{|l|l|}
\hline Basic Mindsets & Deliberative Elaboration \\
\hline Socially self-protective & Vicious Imagination \\
\hline Safety: Bunker Morality (aggression) & Detached Imagination \\
Safety: Wallflower Morality (withdrawal, & \\
appeasement) & \\
\hline Socially-open & Communal Imagination \\
\hline Engagement (relational attunement) &
\end{tabular}




\section{Table 2. Characteristics of Cultural Creatives (Ray \& Anderson, 2000)}

Care deeply about the natural world

Awareness of and desire for action on planet-wide issues (global warming, poverty, etc)

Activism for positive social change

Willingness to pay higher taxes for the benefit of the environment

Value developing and maintaining relationships

Value helping others

Volunteer for good cause

Value spirituality (but fears fundamentalism)

Value spiritual and psychological development

Value equality for women in all spheres

Concerned for the wellbeing of women and children

Want government to focus on education, welfare and sustainable living

Unhappy with left and right politics

Optimistic about the future

Desire to create better way of life for all

Concerned about corporate profit motives and destructive side effects

Unlikely to overspend or be in debt

Deplore emphasis on consumption, status and monetary success

Enjoy exotic people and places 
Figure 1

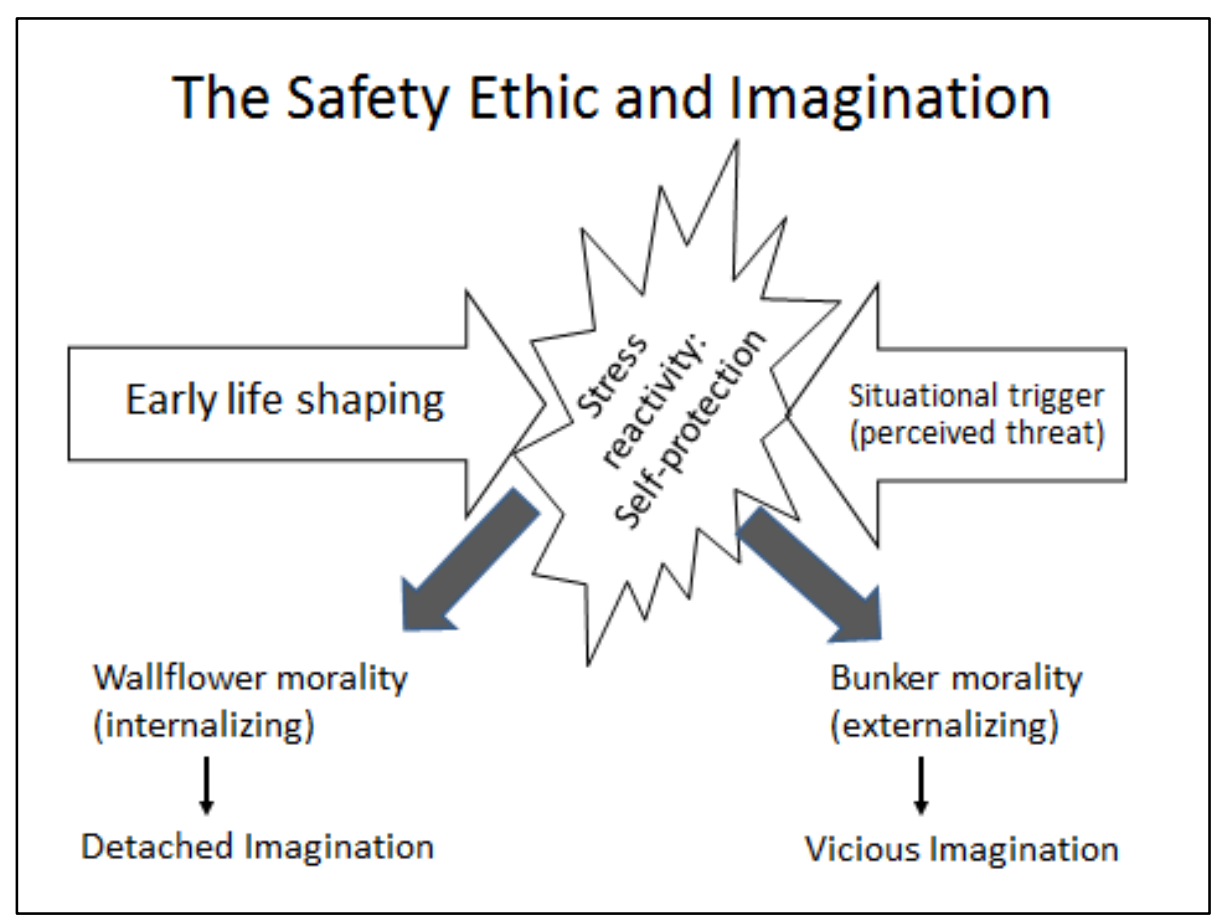

The Engagement Ethic and Imagination

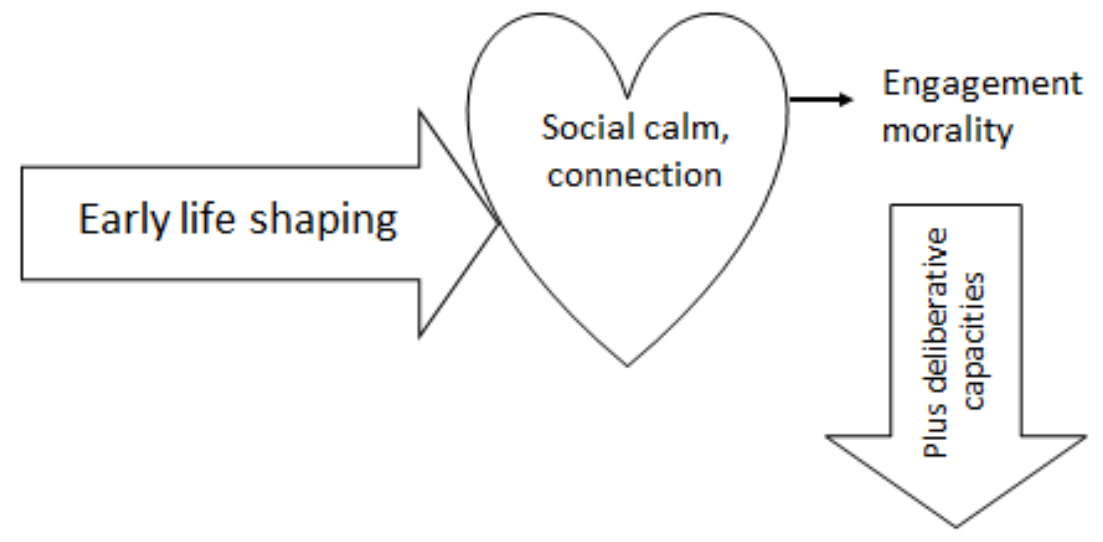

Communal Imagination 